\title{
A Viagem à Itália e a estética goethiana
}

Wilma Patricia MaAs -

É possível abordar a experiência estética de Goethe a partir da perspectiva de sua relação com a forma. Na expressão que serve de título a este artigo, Goethe resume sua experiência na Itália como formreich, rica em formas. Sob o termo, podemos entender tanto a diversidade de objetos da Antiguidade e da Renascença que Goethe teve sob os olhos, como uma alusão à oscilação entre o belo, rico em formas, e o sublime, o informe (gestaltlos). Esse é o fio condutor que seguimos aqui. A forma guia a experiência com os objetos e fenômenos, seja por meio de julgamentos espontâneos seja por meio de ponderações acrescidas posteriormente ao texto, imbuídas já da reflexão.

\section{O incomensurável, a natureza e o sublime}

São frequentes, no texto de Viagem à Itália, as declarações de Goethe quanto à incapacidade dos sentidos de medir, representar, narrar ou descrever certos objetos e fenômenos, devido a sua magnitude, variedade e/ou incomensurabilidade. Os exem- 
plos são muitos. O primeiro é o mais importante, por se tratar da primeira vez em que Goethe visita um monumento autêntico da Antiguidade, o Anfiteatro de Verona, em 16 de setembro de 1787. Depois de se rejubilar com o bom estado em que se encontra a obra, acentuando ser essa a sua primeira experiência frente a um monumento antigo, Goethe passa a discorrer sobre o tamanho descomunal do anfiteatro, que contempla de cima, sobre um dos níveis das arquibancadas:

Assim que entrei, melhor dizendo, quando de cima dei a volta ao edifício pareceu-me estranho estar vendo algo enorme e ao mesmo tempo não estar vendo nada. Não é uma construção par ser vista vazia, mas sim cheia de gente [...]. O povo fica perplexo ao se ver a si mesmo, quando se junta em multidões. Pois, acostumado a se ver andando disperso, vê-se agora, em volteios desordenados, essa manada extraordinária, esse animal vagante de muitas cabeças e muitos sentidos, indo de lá para cá, reunido agora em um organismo nobre, tornado em unidade, amalgamado e solidificado em uma massa, em uma forma habitada pelo espírito. A simplicidade da forma oval é perceptível aos olhos e pode ser experimentada da maneira mais agradável aos sentidos, sendo que cada cabeça é em si uma medida de quão extraordinariamente grande é o todo. Mas agora, ao vê-lo vazio, não se tem a medida, não se sabe se o anfiteatro é grande ou pequeno. (Goethe, HA, 2002, p. 40)

Muitas vezes, Goethe se valerá de expressões semelhantes 
para dar vazão à perplexidade que se segue a sua contemplação dos edifícios muito grandes, das abóbadas muito altas, dos grandes espaços erguidos ao ar livre. Em Pádua Goethe é surpreendido pelo "tamanho descomunal" da sala de audiências do Conselho Municipal:

A sala de audiências do Conselho Municipal, chamada com justiça de Augmentativum Salone,é um espaço fechado de tamanho descomunal, difícil de se imaginar, também impossível de ser reproduzido na memória , mesmo que na mais recente.. (Goethe. HA, 2002, p. 62)

A primeira citação permite que se entenda a descrição do Anfiteatro de Verona como um objeto que desperta o prazer negativo do sublime ligado à ausência de forma e à quantidade. Vazio, o anfiteatro é informe e ilimitado. Parece estar-se vendo algo enorme a ao mesmo tempo, não se estar vendo nada. Cheio, essa ausência de forma e essa ilimitação tornam-se belas, uma forma habitada pelo espírito. No entanto, são poucos os momentos do texto de Viagem à Itália Goethe em que Goethe relaciona nominalmente o termo "sublime" (das Erhabene) com a experiência subjetiva do abalo provocado pela natureza tremenda ou pela arte. Ainda assim, o texto é rico em ocorrências de descrições desse tipo, seja diante de uma erupção vulcânica, seja na descrição de uma tela de um pintor inglês que representa o dilúvio, seja diante dos monumentos da Antiguidade, como o estádio de Verona. Segundo o Dicionário Goethe, são 370 ocorrências do termo "das Erhabene" em Goethe, e, na maior parte delas, cerca de um terço, no sentido de 
"qualidades humanas como grande, nobre (dotado de espírito), significativo, frequentemente com ênfase no caráter moral". Em segundo lugar, aparece o termo como designação atribuída a pessoas "respeitáveis, de grande distinção social, de alta hierarquia, em geral um epíteto destinado a príncipes ou soberanos." Por fim, a acepção que permeia sua compreensão do sublime subjetivo é definida pelo Dicionário Goethe como "incomensurável ou infinitamente grande(e tremendo), frequentemente na forma das Erhabene; em geral, empregado com referência à natureza e a Deus, na maior parte das vezes como uma manifestação desafiadora e percebida de modo ambivalente pelo espírito humano; ocorre frequentemente em reflexões, especialmente sobre a relação com o monstruoso ou insólito [Ungeheuren], nem sempre fácil de diferenciar do próprio sublime [Erhabenen]. ${ }^{1 "}$.(Goethe Wörterbuch, 1999, p. 304)

Essa definição, extraída do próprio uso semântico em Goethe, é a que orienta seus encontros com objetos que escapam à sua capacidade de expressão verbal ou de reconstituição na memória e na imaginação, ainda que o termo seja poucas vezes usado. Mas não são apenas as grandes extensões construídas pelo homem que escapam de sua capacidade de apreensão sensível. Também a riqueza da terra cultivada, a grandiosidade do mar e a violência da montanha fumegante escapam a sua capacidade discursiva:

${ }^{1}$ O Dicionário Goethe afirma que "a obra de Pseudo-Longino Do sublime [Vom Erhabenen] que teve grande influência no século 18 e foi propagada por Bodmer e Breitinger, não teve "qualquer papel no uso que Goethe dez do termo. Ao contrário, foi importante, desde a juventude até a idade avançada, a tematização da dominação do monstruoso/tremendo-sublime por meio da arte, que mais tarde adquirirá, para Goethe, por meio das Críticas kantianas, um fundamento ético." 
Ainda que eu queira escrever palavras, a mim aparecem sempre imagens aos olhos, da terra frutífera, do mar sem limites, das ilhas perfumadas, da montanha que expele fumaça, sendo que me faltam os sentidos capazes de representar tudo isso. (Goethe, HA, 2002, p. 209).

É, entretanto, no sublime apresentado na arte que Goethe se aproximará do sublime da natureza bruta como o descrevera Kant. Na pintura, o impacto causado pela representação do terrível pode ser contemplado "a distância", o que preserva a racionalidade daquele que o contempla, afastando o temor:

Estive depois com Angélica em vista ao inglês Moore, um pintor de paisagens, cujos quadros em sua maioria têm uma composição bastante afortunada. Entre outras coisas há uma pintura do Dilúvio que é algo único. A contrário de outros, que pintam um mar aberto, o que dá sem dúvida a ideia de amplitude, mas não de altura das águas, ele imaginou um vale isolado entre as montanhas, no qual as águas crescentes, acabam por irromper. Pela forma das rochas pode-se perceber que o nível das águas se aproxima do cume. Isso causa um efeito amedrontador, uma vez que o vale se fecha em diagonal e as rochas são muito íngremes. O quadro todo é em tons de cinza, a água suja e revolta une-se à chuva que cai, e as formidáveis massas de água caem das montanhas como se quisessem diluir-se também no elemento universal. O sol brilha como uma lua pálida sobre o corredor de água, sem 
iluminar nada, e ainda nem mesmo é noite. No centro do primeiro plano há uma superfície isolada de rocha plana, sobre a qual alguns infelizes buscam salvar-se, pois as águas subirão e cobrirão a todos. (Goethe, HA, 2002, pp. 366-367)

Percebe-se aí que Goethe busca, algo intencionalmente, a representação do sublime na natureza bruta. Uma vez que o próprio Dicionário Goethe aponta para uma afinidade do sublime em Goethe com a Crítica de Kant, seguimos então trechos da Analítica do sublime para encontrar ali a possível fonte filosófica das descrições do sublime da natureza em Viagem à Itália. Apenas a natureza bruta pode apresentar o sublime, pois, diferente dos "produtos da arte (edifícios, colunas, etc.), onde um fim humano determina tanto a forma como a grandeza, [ou das] coisas da natureza, cujo conceito já comporta um fim determinado (por exemplo, animais de conhecida determinação natural", a natureza bruta, enquanto ela "não comporta nenhum atrativo ou comoção por perigo efetivo", simplesmente contém grandeza. "Pois nesta espécie de representação a natureza não contém nada que fosse monstruoso (nem o que fosse suntuoso ou horrível); a grandeza que é apreendida pode ser aumentada o quanto se queira, desde que, somente, possa ser compreendida pela imaginação em um todo. [....] Um juízo puro sobre o sublime [...] não tem que ter como fundamento de determinação absolutamente nenhum fim do objeto, se ele deve ser estético, e não mesclado com qualquer entendimento do juízo ou da razão. (Kant, 1999, p. 99). Aquilo que à primeira vista parece ser um problema quanto à anteriormente afirmada afinidade entre o sublime goethiano e sua fonte kantiana, pode ser explicado por meio do 
seguinte argumento: se Kant afirma que "não se tem de apresentar o sublime em produtos da arte [...] onde um fim humano determina tanto a forma como a grandeza, nem em coisas da natureza cujo conceito já comporta um fim determinado", a descrição de um quadro, produto da arte humana, poderia ser entendido como um objeto capaz de apresentar esse sublime? Ora, ao contrário de edifícios e colunas, os exemplos da arte humana citados por Kant, a pintura não possui ela mesma uma finalidade. Ela é simplesmente um suporte material no qual Goethe poderá apreciar, com distanciamento, a grandeza que emana do suposto horror ali representado. Pois

Rochas que pendem audaciosamente em direção ao abismo, nuvens tempestuosas que se chocam no céu, provocando raios e trovões, vulcões em sua plena força destruidora, furacões que deixam atrás de si a devastação, o oceano sem limites que cresce incessantemente, a imensa queda d’água de um rio poderoso e outras coisas semelhantes contrariam nossa capacidade de percepção, tornando tudo o mais uma insignificância em comparação com seu poder. Mas contemplá-los se torna ainda mais agradável, por mais temíveis que sejam, quando nos encontramos em segurança, deixandonos descobrir em nós uma capacidade totalmente diferente, que nos encoraja a nos medirmos com o que parece ser a violência da natureza. (Kant, 1957, p. 185).

Na descrição do quadro, Goethe, repetindo quase literalmente o trecho de Kant, a natureza representada não permite que se 
instale o temor que as forças brutais da natureza provocariam no espectador, pois este se encontra em segurança, distanciado, em uma relação mediada pela arte.

\section{Catolicismo, desvario e grotesco}

Mas não são apenas os objetos da Antiguidade e a diversidade da natureza que comovem e alimentam a percepção de Goethe na Itália ${ }^{2}$. Roma, como o centro do catolicismo, produz um efeito intenso e paradoxal na sensibilidade do autor. Os excessos imagéticos e êxtases místicos que Goethe presencia nas missas e celebrações católicas, o culto às relíquias e o testemunho de atos prodigiosos são sintetizados em uma breve narrativa inserida no texto de Viagem à Itália, na qual Goethe narra a biografia de "Filippo Neri, o santo brincalhão", um monge dominicano do século dezesseis. Em um registro que oscila entre a galhofa e a perplexidade e mesmo a admiração, somos apresentados a esse homem, líder da irmandade dominicana no século XVI e personagem de uma Roma mais do que católica, supersticiosa e crente. A Neri eram atribuídos inúmeros talentos misteriosos, como a capacidade de levitar, o êxtase religioso e a capacidade de conjurar e exorcizar espíritos:

${ }^{2}$ Uma declarada antipatia pelos excessos da igreja especialmente ao que diz respeito ao uso de símbolos como a cruz e figuras de santos, será desenvolvida mais tarde no romance Os anos de aprendizado de Wilhlem Meister, no capitulo da Bela Alma, onde se narra o distanciamento progressivo de uma mulher em relação aos símbolos da fé. Ainda que ali se trate da fé pietista, Goethe demonstra a mesma aversão ao apego aos objetos sensíveis como intermediários da fé. 
É certo que, para ser capaz dessas ousadias e ser ainda assim capaz de atos moralíssimos, é preciso ser um grande homem como Filippo Neri, cujas ações muitas vezes foram tomadas por milagres. [...] . Suas orações fervorosas, feitas em êxtase, por parecerem sobrenaturais, colocavam a audiência em um estado de perplexidade, no qual as pessoas acreditavam estar experimentando com os sentidos aquilo que a imaginação, provocada pela emoção, configurava em seus espíritos. (Goethe, HA, 2002, p. 469.)

Esse pequeno trecho permite que se identifique um motivo comum em Goethe, que reconhece a vulnerabilidade dos sentidos frente a uma capacidade de imaginação inflamada.

A isso ainda se junta o fato de que o extraordinário, até mesmo o impossível contado e recontado, acabe por tomar o lugar do que é real é cotidiano. Dentre essas histórias conta-se que não apenas o povo o teria visto em diferentes ocasiões elevar-se por sobre o altar, mas também se encontrariam testemunhas que o teriam visto elevar-se do solo certa vez em que se encontrava ajoelhado à cabeceira de um doente, tocando então o teto com a cabeça. Em um tal estado completamente devotado à emoção e à imaginação, parecia bastante natural que não faltasse ainda a intromissão de espíritos contraditórios. O piedoso homem teria ainda avistado certa vez um espírito contraditório, de aparência simiesca, coxeando por entre ente as ruínas dos banhos antoninos, que desaparecera entre as 
ruínas e colunas fendidas ao ouvir-lhe a voz. Mais importante, porém, do que esse fato isolado, são os testemunhos calorosos de seus discípulos, os quais teriam sido agraciados por meio dos procedimentos do mestre com visões beatíficas como da mãe de Deus e outros santos. Ele, ciente de que de figurações desse tipo são capazes de provocar uma espécie de vaidade intelectual e espiritual, assegurou que, por trás dessa claridade e beleza celestiais, ocultava-se a mais terrível treva. A fim de prová-lo, aconselhou-os a cuspir diretamente no rosto de tão adorável virgem, se sua imagem voltasse a lhes aparecer. Eles obedeceram-no, e deu-se que o sucesso comprovou-se, quando no lugar dela surgiu uma larva do diabo". (Goethe, HA, 2002, p. 470).

O misto de ironia e perplexidade com que Goethe trata os rituais da religião católica nesta sua Viagem à Itália permite, ainda, que se vislumbre uma provável inspiração para o regime das manifestações fantasmagóricas que habitam os seus Faustos. Veja-se o episódio "Cozinha da bruxa" do primeiro Fausto, no qual criaturas simiescas e coxeantes fazem intenso contraste com o espectro ideal de Helena, ou ainda o episódio dos lêmures ("Inumação" e "Grande átrio do palácio") no segundo Fausto, para citar apenas dois exemplos. Aqui, essas imagens harmonizamse com a dicção presente na narração de Viagem a Itália, no qual os excessos da mitologia católica são apresentados sob uma perspectiva jocosa e mesmo com algum desprezo. Da mesma forma que a Itália lhe trouxe a experiência estética da Antiguidade, trouxe-lhe também os excessos visuais e extáticos do 
catolicismo. A narrativa sobre Filippo Neri, o santo brincalhão, sintetiza as observações encontradas ao longo de todo o texto, já desde os primeiros dias da primeira temporada romana. Mesmo no Vaticano, fascinado pela pompa e hierarquia das cerimônias católicas, Goethe revela seu desagrado frente aos excessos de devoção pelas imagens, sugerindo até mesmo que, a seu ver, as obras da Renascença, como os afrescos de Rafael, estariam sofrendo dano físico causado pelo excesso de devoção dos crentes, pela fumaça das velas. Nem mesmo o Papa escapará do "pecado original" do protestante Goethe, que vê o Santo Padre "zunindo e sussurrando de um lado para o outro", ao passo que o autor esperava que ele "abrisse sua boca dourada e nos deleitasse a todos". (Goethe, HA, 2002, p. 127).

A dicção de Goethe para falar sobre os excessos do catolicismo é muito próxima daquela que ele usará para descrever aquele conjunto que talvez seja o mais inesperado nessa narrativa. O Palácio do Príncipe Pallagonia, em Palermo, dá origem a uma descrição do aspecto grotesco, como que uma extensão da percepção sobre os excessos religiosos, não faltando mesmo ao fim uma fusão entre ambos. É possível ter a medida de sua aversão "clássica" ao estilo moderno e grotesco da construção e decoração dos salões, uma espécie de sarabanda demoníaca onde épocas e estilos se encontram misturados e empilhados uns sobre os outros, como se pode ler na saborosa descrição que segue:

A fim de narrar em toda a sua extensão os desvarios do príncipe, fornecemos uma espécie de inventário. Figuras humanas: mendicantes do sexo masculino e feminino, espanhóis e espanholas, turcos, corcundas, todo 
tipo de deformações, anões, músicos, polichinelos, soldados em trajes antigos, deuses e deusas, gente vestida à antiga maneira francesa, soldados carregando as sacolas de munição e calçando coturnos, mitologia misturada a ingredientes farsescos: Aquiles e Quíron junto com Polichinelo. Animais: apenas partes, cavalos com mãos humanas, macacos deformados, muitos dragões e serpentes, todo os tipos de patas nas mais diferentes figuras, duplicação e troca das cabeças. Vasos: todo tipo de monstros e arabescos, que terminavam lá em baixo no ventre dos vasos e nos suportes sob eles. .Pense-se em tais figuras, empilhadas umas sobre as outras, surgidas sem qualquer espírito ou racionalidade, e reunidas também sem escolha prévia ou intenção, imagine-se esses pedestais e outras deformidades alinhadas a perder de vista e de modo desconexo, então será possível compartilhar o sentimento desagradável que acomete aquele que se vir perseguido por essas chicotadas desferidas pelo desvario.[...] O que há de mais avesso aos sentidos nessa forma de pensar é o fato de que as cornijas das casinhas pendem para um lado ou para o outro, de modo que o sentido para o nível horizontal e para a direção perpendicular, que nos tornam propriamente humanos e constituem a base para todo equilíbrio e harmonia é em nós destruído e torturado. Da mesma forma, também essa sequência de telhados é toda enfeitada com hidras e pequenos bustos, com coros de macacos fazendo música e outros disparates semelhantes. Dragões e deuses intercalam-se, um gigante Atlas traz nos ombros um 
barril de vinho, em lugar da esfera celeste. (Goethe, HA, 2002, pp. 244-245)

\section{O Carnaval romano. Alegoria e licenciosidade}

Aversão e deslumbramento serão relatados também no excerto sobre o carnaval romano, que Goethe vivenciou por duas vezes. Seu relato refere-se à segunda, em fevereiro de 1787, dois meses antes de sua partida de Roma. Sob a perspectiva de Goethe, trata-se de um desfile desvairado que agrega uma literalmente incalculável multidão de gente a um regime de tempo antinatural, em que a ordem das coisas é, também literalmente, abolida. A ambiguidade sexual das fantasias, a promessa de licenciosidade e uma tendência à infração e mesmo ao crime fazem dessa descrição um belo exercício para as cenas fáusticas, ao mesmo tempo em que familiarizam o autor com alegorias avant la lettre. O primeiro parágrafo da narrativa resume o sentimento dúbio que essa festa dos sentidos provoca no "cimério":

Ao nos propormos a descrever o Carnaval romano, devemos esperar objeções quanto ao fato de que uma festa como essa não pode ser descrita. Uma tal massa viva de tantos objetos sensuais deveria movimentar-se apenas imediatamente frente aos olhos e ser contemplada e abarcada por cada um à sua maneira. Tornase ainda mais série essa objeção quando somos nós mesmos obrigados a confessar que, para um espectador estrangeiro que o vê pela primeira vez, o Carnaval 
romano não oferece uma impressão alegre, não oferece consolo aos olhos nem tranquiliza a alma. Não se vê mais a longa e estreita rua, coberta que está por uma multidão que se agita de um lado para o outro; mal se distingue alguma coisa em meio a esse tumulto, algo que os olhos possam fixar. O movimento é monótono, obtuso, o barulho, ensurdecedor e o fim do dia deixanos em um estado de grande intranquilidade e insatisfação. Todas essas objeções, entretanto, são anuladas quando contemplamos mais de perto. E agora tratemos de ver aonde chegamos com a descrição. (Goethe, HA, 2002, p. 484)

Essa passagem reforça a incapacidade da percepção pelos sentidos e da reprodução discursiva do impacto e incômodo provocados seja pela multidão informe, fenômeno que Goethe só conhecerá na Itália, seja pelo excesso de estímulos sensuais. Também mais suma vez, a oscilação entre o belo e o terrível se faz presente, bastando que se altere a disposição subjetiva de quem contempla.

Dentre o elenco de tropos adversos que passam a ser considerados como belos, está a alegoria. No final da década de oitenta, em textos como "Sobre os objetos das artes figurativas", Goethe criticara os procedimentos alegóricos, seja como tropo literário, seja nas artes plásticas. Já no texto de Viagem à Itália, serão bem vindas alegorias literais como a "musa da história da arte", " a musa trágica", "a musa da História", "uma cidade", todas consideradas agora "formas nobres". (Goethe, HA, 2002, p. 510).

Por fim, é preciso lembrar como o Carnaval romano fornecerá suporte material para uma ideia presente já em Os anos de 
aprendizado de Wilhelm Meister, que vem à público oito anos depois: as relações amorosas travadas entre membros de diferentes estamentos:

Da mesma forma, os trajes costumeiros de todas os estamentos da sociedade podem servir como fantasias. Empregados de estábulo vêm, munidos de suas grandes escovas, para escovar as costas de quem bem lhes aprouver. Cocheiros oferecem seus serviços com sua costumeira grosseria. [...]A distinção entre as camadas mais elevadas e as mais baixas parece anulada por um instante. Todos se aproximam de todos, cada um pega aquilo que vem a seu encontro, facilmente, e a ousadia e a liberdade alternam-se, sendo equilibradas por um bom humor geral. (Goethe, HA, 2002, p. 493).

O trecho poderia ser ilustrado, sem qualquer prejuízo, pelos pares amorosos que se formam no segundo romance do Meister, como os jocosos Philine e Friedrich ou mais graves Wilhelm e Natalie, uniões que foram saudadas por críticos como Bernd Witte como uma resposta (estética, não política) de Goethe aos eventos da Revolução Francesa.

\section{Diversidade botânica e planta primordial}

Em Nápoles e na Sicília, Goethe encontrará a diversidade natural que o levará a conceber finalmente sua ideia de planta primordial. Já antes, em Pádua, em setembro de 1786, Goethe, em visita ao jardim botânico, afirmava ser 
muito prazeroso e instrutivo caminhar por uma vegetação que não nos é familiar. Quando nos deparamos com espécimes costumeiros, assim como com objetos há muito conhecidos, não pensamos em nada, mas o que é a contemplação sem o pensamento? Aqui, junto a essa diversidade que se me apresenta pela primeira vez, torna-se cada vez mais viva aquela ideia segundo a qual todas as formas vegetais talvez pudessem derivar de uma única. Somente desse modo seria possível determinar verdadeiramente gêneros e espécies, penso eu, o que, até então, vem sendo feito de modo bastante arbitrário. É exatamente nesse ponto que me encontro estacado em minha filosofia botânica, sendo que ainda não vislumbro como sair dele. (Goethe, HA, 2002.p. 60, grifo meu)

Mais tarde, em maio de 1787, de Nápoles, Goethe escreve a Charlotte von Stein, pedindo-lhe que informe a Herder que se encontra "muito próximo do segredo da geração e organização das plantas", e que se trata da coisa mais simples que se poderia pensar:

Sob este céu é possível fazer as mais belas observações. Diga-lhe [a Herder] que já não tenho mais dúvidas, que descobri claramente onde se encontra o cerne das coisas, diga-lhe que agora sou capaz de contemplar tudo o mais no Todo e que apenas alguns pontos precisam ainda de melhor definição. A planta primordial será a criação mais prodigiosa do universo, pela qual a própria natureza deverá invejar-me. Com esse modelo e 
com a chave de acesso a ele pode-se descobrir um número infinito de plantas, em uma série consequente. Isso quer dizer que, mesmo que não existam, sua existência seria certamente possível, não como sombra e aparência artística ou poética, mas sim dotadas de uma verdade e necessidade interna. (Goethe, HA, 2002, pp. 323-324).

Ambos os trechos são muito significativos no que diz respeito à geração de uma noção central do pensamento científico goethiano, que, como se sabe, se expressa em geral por meio de uma linguagem imagética. A possibilidade de fazer coincidir a simultaneidade e a sucessividade, a diversidade e a organicidade será, de uma vez por todas, condensada na intuição da planta primordial, que Schiller, em 1794, chamará de "meramente uma ideia". A afirmação de Schiller legitima a hipótese de que o pensamento de Goethe é sempre mediado pela capacidade de gerar imagens, seja a partir da natureza, seja a partir dos objetos artísticos. Sua velha "obsessão" pela busca da forma original é então alimentada pela diversidade encontrada na vegetação siciliana. Em abril de 1787, em Palermo, enquanto buscava concentrar-se na ideia do drama de Nausícaa, Goethe é mais uma vez assaltado pelas imagens, que tornam ainda mais firmes sob a convicção da real existência da planta primordial.

É um verdadeiro infortúnio ser perseguindo e seduzido por uma horda de espíritos! Dirigi-me hoje de manhã ao jardim público com o firme propósito de dar continuidade a meus devaneios poéticos, mas, antes que eu me desse conta, uma outra aparição apropriou-se 
de mim, a qual vem me acompanhando nestes últimos dias. As muitas plantas que tenho visto apenas em vasos e cubos, na maior parte do ano apenas através do vidro das estufas, encontram-se aqui vivas e alegres a céu aberto e ao cumprir assim completamente o seu destino, tornam-se mais nítidas e visíveis para nós. À vista da uma imagem de tanta coisa nova e renovada ocorreu-me novamente a velha obsessão): se entre essa miríade de plantas não se poderia encontrar a planta primordial. Pois ela deve realmente existir! Como eu poderia reconhecer que este ou aquele construto é uma planta, se não fossem todas elas formadas a partir de um modelo? (Goethe, HA, 2002, p. 266).

\section{Epopeia siciliana. Goethe como Ulisses}

Dentre as muitas obsessões goethianas, a temporada na Sicília forneceu-lhe ainda a paisagem ideal para o que ele chamou uma concentração dramática da Odisseia, que considerava "possível, contanto que que não se perca dos olhos a grande diferença entre o drama e a epopeia.'Movido pela paisagem e atmosfera mediterrânea, Goethe retoma sua leitura de Homero, propondo-se à dramatização do tema de Nausicaa, :

A claridade do céu, o hálito marinho, os odores, por meio dos quais as montanhas, o céu e o mar se diluem em um único elemento, tudo serve de alimento a meus propósitos. E quando vagueei por entre este belo jardim público, entre florescentes oleandros, por 
entre as copas carregadas das laranjeiras e limoeiros, detendo-me junto a árvores e arbustos que eu desconhecia, senti a influência estrangeira da maneira mais prazerosa. Convencido de que esta viva paisagem seria o melhor comentário à Odisseia, consegui um exemplar e li-o, segundo meu hábito, com grande envolvimento. Logo senti-me instado a produzir uma obra própria, a qual, por mais singular que possa ter parecido em um primeiro momento, sempre me fora cara e acabou por ocupar-me completamente. Foi quando concebi o pensamento de tratar de modo trágico o tema de Nausícaa. (Goethe, HA, 2002, pp. 298-299).

A identificação de Goethe com o tema e o cenário é tão intensa que ele chega mesmo a se comparar a Ulisses, o estrangeiro incógnito.

A aludida dificuldade de se determinar a que gênero pertence o texto publicado como Viagem a Itália advém, como já se disse, do caráter enciclopédico dos relatos reunidos em um mesmo texto, assim como das diferentes épocas em que foram compostos e inseridos. Buscou-se aqui acompanhar uma linha mestra que possa, se não dar unidade e harmonia ao texto, algo que na maior parte das vezes não é possível, quando se trata de Goethe, dar a medida das preocupações do autor quanto a sua própria atividade e reflexão estética. Na "mitologia" goethiana, Viagem à Itália é um testemunho autobiográfico do mesmo peso de Poesia e verdade; aqui, entendemos o texto da experiência italiana como mais uma de suas obras enciclopédicas, na qual a forma e a contemplação têm lugar predominante. 


\section{Referências Bibliograficas}

GOETHE, J. W. Hamburger Ausgabe (HA), vol 11. C.H. Beck, Munique, 2002.

. Münchner Ausgabe (MA), Hanser, vol 3/2, 1990.

KANT, I. Kritik der Urteilskraft. Weischedel, W. (ed.). Darmstadt, 1957.

Goethe-Wörterbuch. vol. 4, 2a. Edição. Stuttgart, Berlin, Köln, 1999. 